\title{
ERRATUM
}

\section{Genetics of MuB1 and of a complement defect in inbred strains of mice}

\author{
By B. CINADER, S. DUBISKI AND A. C. WARDLAW
}

Volume 7, No. 1, p. 37 (1966): Table 4 should read:

Table 4. The distribution of $M u A 2$ and $M u B 1$ in several inbred strains of mice MuA2-positive strains

MuBl-negative

NBL/N, NS/Fr, PHH

\author{
MuB1-positive \\ C57BL/6J, C57BL/10J, \\ HR/De, SJL/J, SM/J, \\ WH/Ht
}

MuA2-negative strains

MuB1-negative

$\mathrm{A} / \mathrm{J}, \mathrm{A} / \mathrm{HeJ}, \mathrm{AKR} / \mathrm{J}, \mathrm{AU}, \mathrm{BUA} / \mathrm{Wi}$, BUC/Wi, BUE/Wi, CE/J, DB/Sp,

DBA/2J, DDK, DM/Ms, FAKI, GFF, IF/Bcr, I/FnLn, JU/Fa, KK, $\mathrm{MaS} / \mathrm{A}, \mathrm{NC}, \mathrm{NZB} / \mathrm{Bl}, \mathrm{RF} / \mathrm{J}$, SMA/Ms, $\mathrm{ST} / \mathrm{J}, \mathrm{SWR} / \mathrm{J}, \mathrm{YBR} / \mathrm{HeWiHa}$
MuBl-positive

BALB/cJ, BDP/J, BRVR/Sr, BSVS/Sr, $\mathrm{BUB} / \mathrm{Bn}, \mathrm{BUB} / \mathrm{Bn}-C, \mathrm{BUB} / \mathrm{Wi}, \mathrm{CBA} / \mathrm{J}$, C3Hf/BiOci, C3H/HeJ, CHI/St, C57BR/cdJ, C57L/J, C58/J, DBA/lJ, F/St, FU, MA/J, MO/Ko, NZO/B1, PE/RI, PHL, P/J, PL/J, PS, RIII/J, SEA/Gn-se, SEC/1Gn, SL/R1, STOLI/Lw, T6, 129/J, 2BC3/H, 2C3H 
Plates should only be included where absolutely essential. They should be supplied as unmounted glossy prints; any lettering to be inserted on them is best indicated on a separate sketch. Please do not damage prints by writing heavily on their backs or by using paper clips.

DIAGR A MS should be about twice the size of the finished block, and the thickness of lines and size of points determined accordingly. They must be drawn in Indian ink on white Bristol Board or tracing linen; graph paper ruled in pale blue (but not other colours) is also acceptable. Lettering should be lightly inserted in soft pencil only, so that the printer can put in the finished lettering.

Legends to illustrations must be given on a separate sheet of paper. Each illustration must have the name of the author and figure number pencilled on the back. Plates and diagrams should be numbered separately and their position indicated on the typescript. It will hasten refereeing if a photograph of each diagram can be supplied with the carbon copy of the paper.

TABLES should each be typed on a separate sheet of paper and their approximate positions in the text indicated on the typescript. Each table should be numbered and carry an appropriate title. The table should be designed, whenever possible, to be printed in the normal orientation of the text. The data should be grouped so as to make the use of rules unnecessary. Vertical rules, in particular, are expensive to print, and will only be included at the Editor's discretion.

Footnotes should be avoided where possible. They can often be incorporated into the text, in parentheses.

SумвоLs. Italic letters should generally be adopted for both gene symbols and quantities in mathematical formulae. Bold letters add to printing costs, and should only be used where they are necessary to avoid confusion.

SPELLING should follow the Concise Oxford Dictionary.

REFERENCES should follow the normal usage in the journal. In the list of references at the end of the paper, titles of periodicals should be abbreviated according to the World List of Scientific Periodicals (fourth edition).

Proors. Two sets of single-sided page proofs, together with the typescript, of each paper will be sent to the author. The printers' marked proof should be returned after correction to the Executive Editor. Excessive alterations, other than corrections of printers' errors, may be disallowed or charged to the author. Correction should be made using the symbols in British Standard 1219: 1958, or its shortened version B.S. $1219 \mathrm{C}$ : 1958.

OFFPRINTs. Fifty offprints of each paper, including short papers, are provided free of charge. Additional offprints may be ordered on the form sent out with proofs, provided this is returned within seven days of receipt. 
VOLUME 9, NUMBER 2, 1967

\section{CONTENTS}

Elston, R. C. and Glassman, E. An approach to the problem of whether clustering of functionally related genes occurs in higher organisms page

DE GRoot, B. The bar-properties, in particular glucosylation of deoxyribonucleic acid, in crosses of bacteriophages T2 and T4

Kruszewska, A. and GaJewskr, W. Recombination within the $Y$ locus in Ascobolus immersus

AHмreD, K. A. and WooDs, R, A. A genetic analysis of resistance to nystatin in Saccharomyces cerevisiae

Simchen, G. Genetic control of recombination and the incompatibility system in Schizophyllum commune

Dunn, L. C. and BenNeTt, D. Sex differences in recombination of linked genes in animals

JoNEs, L. P. Effects of X-rays on response to selection for a quantitative character of Drosophila melanogaster

EDWARDS, K. J. R. Developmental genetics of leaf formation in Lolium. 1. Basic patterns of leaf development in $L$. multiflorum and L. perenne

EdWARDs, K. J. R. Development geneties of leaf formation in Lolium. 2. Analysis of selection lines 